\section{Matters arising}

Recurrent intracranial haemorrhage in Behcet disease

Sir: I read with interest the contribution by Nagata entitled "Recurrent intracranial haemorrhage in Behcet disease".' Nagata attributes the intracranial haemorrhages principally to hypertension and hypertensive arterial changes. I do not think that atherosclerotic embolic disease however has been excluded as a potentiating factor for such a rapid flurry of intracranial accidents. Diffuse disseminated atheroembolisation is a disorder wherein atheromatous fragments chronically shower the peripheral vasculature in small to large numbers, producing radiographic and clinical pictures that are often indistinguishable from lacunar stroke syndrome. Moreover there is a high incidence of gastrointestinal ulceration and inflammation which is often indistinguishable histopathologically from a vasculitis. In addition there is a predilection for the basal ganglia as we recently reported in a study of the neuroophthalmic manifestations of diffuse disseminated atheroembolisation. ${ }^{2}$ I would be most interested to learn if this patient's abdominal aorta had the characteristic "brittle" appearance associated with diffuse disseminated atheroembolisation and if review of the gastrointestinal and kidney slides showed cholesterol clefts in any of the small arterioles.

JAMES R COPPETO 1906 North Main Street Waterbury, Conn. 06704, USA

\section{References}

' Nagata K. Recurrent intracranial haemorrhage in Behcet disease. J Neurol Neurosurg Psychiatry 1985;48:190-1.

2 Coppeto JR, Lessell S, Lessell IM, Greco TP, Eizenberg MS. Diffuse disseminated atheroembolism; three cases with neuroophthalmic manifestation. Arch Ophthalmol 1984; 102: 225-8.

\section{Nagata replies:}

In answer to the letter from Dr Coppeto, there was no pathological evidence of a disseminated atheroembolism in our case. As I have reported, perivascular inflammatory changes in the intracerebral small vessels were in an active stage that could cause organic changes of the vessel wall, and there was much greater evidence of hypertensive vascular changes which are closely associated with hypertensive intracerebral haemorrhage. Although there were small softening foci scattered in the cerebral white matter and in the pons, we did not find cholesterol emboli in these small ischaemic lesions. The abdominal aorta did not have a "brittle" appearance of athrosclerosis. The ulceration and erosion of the gastrointestinal tract were much different from those due to vasculitis or disseminated embolism. There were no cholesterol clefts in the small arteries of the intestine or kidneys as far as we investigated. In addition, the onset age of this patient was much younger than that of reported cases with histopathological features of disseminated atheroembolism. Moreover, in most of the reports concerning intracranial disseminated atheroembolism, the intracranial accidents occurred as a form of cerebral infarction. All three cases of diffuse disseminated atheroembolism reported by Coppeto et al (1984) also showed ischaemic cerebrovascular process. As far as the haemorrhagic lesions in this patient are concerned, it is very hard to substantiate that they were associated with disseminated atheroembolism, which was not proved in any other organs in this patient.

\section{The spoon test for assessing sudomotor autonomic failure}

Sir: I read with interest the reported new "Spoon test" by SA Tsementzis and ER Hitchcock.' This test describes the use of an English kitchen soup spoon but we in the former colonies are familiar with the test using an American teaspoon. This was reported by Doctor Ernest Bors in his book $^{2}$ as follows: "The autonomic deficit can be assessed by determining skin sweating at rest. The simplest clinical examination consists of letting the convexity of a teaspoon glide by its own weight over the skin in a zigzagging fashion. When the spoon starts sticking to the skin, the level of skin moisture has been reached. It is necessary to keep the spoon dry and to exclude contact sweating caused by skin folds (axilla, elbow, inguinal region, flexor surface of the knee) or by bed blankets."

ALVIN D SIDELL, MD

Barrow Neurological Institute St Joseph's Hospital 350 West Thomas $R d$

Phoenix, Arizona 85013 USA

\section{References}

' Tsementzis SA, Hitchcock ER. The spoon test: a simple bedside test for assessin sudomotor autonomic failure. J Neurol Neurosurg \& Psychiatry 1985;48:378-80.

${ }^{2}$ Bors E, Comarr AE. History and Examination. In: Neurological Urology: Physiology of Micturition, Its Neurological Disorders and Sequelae. Baltimore, University Park Press 1971:170.

\section{Hitchcock writes:}

Although unaware of the work at the time we presented our paper it has been brought to our attention that the same test was described more than 20 years ago by Bors.' We did not in our paper therefore attribute, as we should have done, the test to this author but we would like the reference to be generally known and we append it at the end of this letter.

The fact that the test has already been described in no way detracts from presenting the paper which made a critical examination of the accuracy of a test which we believe is so useful it deserves reviving.

\section{Reference}

' Bors E. Simple methods of examination in paraplegia: I. The spoon test. Paraplegia Vol II $1964 ; 1: 17-9$.

\section{Delayed onset dystonia}

Sir: Burke, et al' wrote about eight patients with dystonia appearing one to 14 years after a cerebral insult. Although previous examples of delayed-onset dystonia can be found in the literature, the clinical importance of this phenomenon had not been adequately emphasised. The comprehensive review of the literature of Burke et al failed, however, to quote an earlier description and pathophysiological discussion of delayed-onset dystonia. In 1966, one of us (LBB) reported ${ }^{2}$ two young patients with axial and bilateral upper limb dystonia in whom the diagnosis of idiopathic torsion dystonia had been suggested in view of the normal early development of the distonia and absence of additional neurological signs. A positive history of perinatal anoxia in one and of prolonged and complicated labour in the second patient were the only diagnostic clues in these cases.

We agree with Burke et al in that 